\title{
RESISTÊNCIA DE Eleusine indica AOS INIBIDORES DE ACCASE ${ }^{1}$
}

\author{
Eleusine indica Resistance to Accase Inhibitors
}

\author{
VIDAL, R.A. ${ }^{2}$, PORTES, E.S. ${ }^{3}$ LAMEGO, F.P. ${ }^{3}$ e TREZZI, M.M. ${ }^{4}$
}

\begin{abstract}
RESUMO - Dentre as causas da ineficácia no controle de plantas daninhas destaca-se a resistência delas aos herbicidas. Os objetivos deste trabalho foram avaliar a suspeita de resistência de Eleusine indica a inibidores de acetil-CoA carboxilase (ACCase) e investigar a ocorrência de resistência cruzada entre os inibidores de ACCase. Biótipo de Eleusine indica originado do Mato Grosso com suspeita de resistência aos herbicidas inibidores de ACCase foi avaliado em casa de vegetação na sua suscetibilidade para diversos produtos do grupo dos ariloxifenoxipropionatos e cicloexanodionas. Estudos de resposta à dose confirmaram que o biótipo era 18 vezes mais insensivel ao sethoxydim do que biótipo suscetivel nunca aspergido com herbicidas. Também se constatou resistência cruzada ao fenoxaprop, cyhalofop, propaquizafop e butroxydim. Não se observou resistência cruzada aos produtos fluazifop, haloxyfop, quizalofop e clethodim.
\end{abstract}

Palavras-chave: resistência, herbicidas, planta daninha, gramínea.

\begin{abstract}
Among the causes for weed control inefficacy, the worst one is resistance to herbicides. The objectives of this work were to evaluate an Eleusine indica biotype suspected of resistance to ACCase inhibitors and to investigate the occurrence of cross-resistance to several ACCase inhibitors. One biotype of Eleusine indica originated from Mato Grosso with suspected resistance to ACCase inhibitors was evaluated in a greenhouse in relation to its susceptibility to several products of the ariloxyphenoxypropionate and cyclohexanedione groups. Studies on dose response confirmed that the suspected biotype was 18 times more insensitive to sethoxydim than the susceptible biotype that had never been treated with herbicides. Cross-resistance was confirmed for fenoxaprop, cyhalofop, propaquizafop and butroxydim. No cross-resistance was observed with fluazifop, haloxyfop, quizalofop, and clethodim.
\end{abstract}

Keywords: resistance, herbicides, weed, grass.

\section{INTRODUÇÃO}

Eleusine indica Gaertn (ELEIN, capim-péde-galinha) é uma espécie daninha comum no Sul, Sudeste e Centro-Oeste do Brasil. Seu centro de origem provavelmente é a Ásia e foi distribuída pelas regiões tropicais, subtropicais e temperadas do mundo, com maior presença entre os trópicos de câncer e capricórnio (Kissmann \& Groth, 1992).
Em condições de solo compactado, com baixa fertilidade e elevada acidez, ELEIN leva vantagem competitiva em relação às demais espécies. A taxa de germinação das sementes é inferior a $10 \%$ quando colocadas sob temperaturas constantes entre 20 e $35^{\circ} \mathrm{C}$, enquanto se eleva para 99\% em condições de flutuação térmica. Essa espécie possui fotossíntese do tipo C4; a elevada luminosidade estimula o crescimento e favorece hábito de

1 Recebido para publicação em 16.6.2005 e na forma revisada em 24.2.2006.

2 Eng.-Agr., Ph. D., Professor da Universidade Federal do Rio Grande do Sul - UFRGS, Faculdade de Agronomia, Departamento de Plantas de Lavoura, Caixa Postal 15.100, 90.001-970 Porto Alegre-RS, Bolsista do CNPQ, <ribas.vidal@ pesquisador.cnpq.br>; ${ }^{3}$ Eng.-Agr., M.S., aluno do Programa de Pós-Graduação em Fitotecnia da Faculdade de Agronomia da UFRGS. ${ }^{4}$ Eng.-Agr., Ph.D., Professor da Faculdade de Agronomia do CEFET, 85503-390 Pato Branco-PR. 
crescimento do tipo prostrado, ao passo que o sombreamento origina indivíduos com hábito ereto e de baixo porte (Kissmann \& Groth, 1992). As espécies do gênero Eleusine são diplóides ( $x=9$ ), autógamas e produzem elevada quantidade de sementes, que são disseminadas pelo vento (Kissmann \& Groth, 1992).

No mundo, foram detectados biótipos de ELEIN resistentes aos herbicidas com os seguintes mecanismos de ação (em ordem cronológica de detecção): inibidores de mitose (1973), inibidores de ALS (1989), inibidores de ACCase (1990), inibidores do fotossistema I (1990) e inibidores de EPSPS (1997) (Heap, 2005). Vale ressaltar que essa espécie possui o biótipo com o único caso conhecido de gene recessivo conferindo resistência aos herbicidas inibidores de mitose (Morrissette et al., 2004). Um biótipo coletado na Malásia possui resistência múltipla aos inibidores de ACCase e de EPSPS (Heap, 2005).

A resistência das plantas daninhas aos herbicidas é definida pela FAO como a ocorrência de biótipo com habilidade de sobreviver à aplicação de composto químico, para o qual a população original era suscetivel (LeBaron \& Gressel, 1982). Sua ocorrência foi teorizada por Harper (1956) e documentada pela primeira vez no Canadá e nos Estados Unidos em 1957 (Hilton, 1957; Switzer, 1957). A partir de 1970, os eventos de resistência passaram a ser documentados continuadamente, sendo registrados cerca de 10 novos casos por ano (Vidal \& Merotto Jr., 2001).

No Brasil, já estão documentadas as seguintes espécies resistentes aos herbicidas: Euphorbia heterophylla, Bidens pilosa, Bidens subalternans, Brachiaria plantaginea, Sagittaria montevidensis, Echinochloa spp., Cyperus difformis, Digitaria spp., Fimbristylis miliacea, Parthenium hysterophorus, Raphanus sativus e Lolium multiflorum (Christoffoleti et al., 1996; Gazziero et al., 1998, 2000; Noldin et al., 1999; Vidal \& Merotto Jr., 1999; Merotto Jr. et al., 2000; Cortez et al., 2002; Noldin et al., 2002a,b; Roman et al., 2004). Durante a última década foi documentada anualmente, em nosso país, em média, uma nova espécie resistente aos herbicidas (Vidal \& Winkler, 2004). Recentemente, Trezzi et al. (2005) registraram o primeiro biótipo de espécie daninha com resistência múltipla aos herbicidas.
Os fatores que favorecem a seleção de biótipos resistentes envolvem características relacionadas às plantas daninhas, aos herbicidas e às práticas culturais. A diversidade genética é comum principalmente entre as plantas daninhas anuais e favorece a seleção da resistência ao herbicida. Isso explica, ao menos em parte, por que em nivel mundial a maioria dos biótipos resistentes aos herbicidas é de espécies anuais. Grandes infestações de plantas daninhas favorecem o aumento dos riscos de seleção para resistência (Winkler et al., 2002).

Como os herbicidas são selecionadores dos biótipos resistentes, a intensidade de seleção depende do número de anos de uso de produtos com o mesmo mecanismo de ação em determinada área. O controle de plantas daninhas monocotiledôneas é realizado nas culturas dicotiledôneas - como soja, por exemplo - predominantemente com herbicidas inibidores da enzima acetil-CoA carboxilase (ACCase). Esta enzima catalisa a primeira reação química, a partir de acetil-CoA, para síntese de lipídeos nas células vegetais (Vidal \& Merotto Jr., 2001). Os herbicidas inibidores de ACCase compõem uma das classes mais numerosas de herbicidas registrados atualmente, somando 15 marcas comerciais no Brasil (Vidal, 2002). Suspeitas de ELEIN resistente aos inibidores de ACCase foram detectadas em 2004, em propriedade com cultivo de soja localizada no Estado do Mato Grosso. Os objetivos deste trabalho foram avaliar a suspeita de resistência de Eleusine indica aos inibidores de ACCase e investigar a ocorrência de resistência cruzada entre estes herbicidas.

\section{MATERIAL E MÉTODOS}

Sementes de ELEIN oriundas de aproximadamente 1.000 plantas sob suspeita de resistência aos inibidores de ACCase foram coletadas em abril de 2004, em propriedade rural localizada no Mato Grosso. As áreas onde se encontraram os indivíduos suspeitos estavam sob monocultura de soja por quase duas décadas; nesse período, o controle de gramíneas sempre foi feito com herbicidas inibidores de ACCase.

Sementes de plantas suscetiveis aos herbicidas foram coletadas em área do 
Departamento de Plantas de Lavoura da Faculdade de Agronomia da UFRGS, localizada no município de Porto Alegre, RS. Nesta área não é utilizado herbicida e o controle de plantas daninhas é realizado esporadicamente com método mecânico (roçadeira). Após a coleta, as sementes de ambos os biótipos foram secas ao ar e posteriormente acondicionadas em saco plástico e armazenadas em geladeira com temperatura de $4{ }^{\circ} \mathrm{C}$, até a realização dos quatro experimentos constantes deste estudo.

Sementes de plantas suscetiveis e suspeitas de resistência foram colocadas para germinar em bandejas plásticas de $2.000 \mathrm{~mL}$, sob substrato constituído de solo:areia na proporção de 2:1. Após emergência das plantas, quando estas estavam com quatro folhas, foi realizado o seu transplante para vasos com capacidade de $300 \mathrm{~mL}$ com o mesmo substrato já descrito. Colocou-se uma planta por vaso e os vasos foram mantidos em bandejas plásticas contendo água, para manter as plantas irrigadas. As temperaturas diurna e noturna da casa de vegetação foram de $29 \pm 5$ e $20 \pm 6{ }^{\circ} \mathrm{C}$, respectivamente.

O primeiro experimento foi realizado com a população resistente, a fim de investigar quais, entre os inibidores de ACCase, eram prováveis candidatos à resistência, ou seja, avaliou-se a resistência cruzada para diversos herbicidas inibidores de ACCase. Utilizou-se delineamento inteiramente casualizado (DIC) com três repetições. Aos 10 dias após o transplante das plantas, quando elas estavam com um afilho, aplicaram-se os seguintes herbicidas e respectivas concentrações, assumindo o volume de calda de $100 \mathrm{~L} \mathrm{ha}^{-1}$ (doses em parênteses): clethodim $\left(3,3 \mathrm{mM}=120 \mathrm{~g} \mathrm{ha}^{-1}\right)$, cyhalofop (15,9 mM = $\left.240 \mathrm{~g} \mathrm{ha}^{-1}\right)$, fenoxaprop-p (6,5 mM $\left.=220 \mathrm{~g} \mathrm{ha}^{-1}\right)$, fluazifop $\left(7,6 \mathrm{mM}=250 \mathrm{~g} \mathrm{ha}^{-1}\right)$, haloxyfop $\left(4,9 \mathrm{mM}=180 \mathrm{~g} \mathrm{ha}^{-1}\right)$, quizalofop $\left(2,9 \mathrm{mM}=100 \mathrm{~g} \mathrm{ha}^{-1}\right)$ e sethoxydim $(7,0 \mathrm{mM}=$ $\left.220 \mathrm{~g} \mathrm{ha}^{-1}\right)$. Em todas as soluções herbicidas foi adicionado o surfatante alqui-nonilpoliglicoléter (250 $\mathrm{g} \mathrm{L}^{-1}$, marca Extravon), na proporção de 0,2\% v:v. Além dos herbicidas, acrescentou-se um tratamento testemunha sem aspersão de produtos. Todas as concentrações selecionadas neste experimento correspondem àquelas usualmente indicadas para uso no campo. Os herbicidas foram aspergidos com equipamento pressurizado por gás carbônico, com pontas de pulverização do tipo leque XR 8001, pressão de $200 \mathrm{kPa}$ e volume de calda de $100 \mathrm{~L} \mathrm{ha}^{-1}$. No momento da aplicação a temperatura do ar era de $29{ }^{\circ} \mathrm{C}$.

Foram avaliadas a fitotoxicidade causada pelos herbicidas (controle de ELEIN) e a massa das plantas desidratadas de ELEIN. O controle destas plantas foi avaliado aos 21, 28 e 35 dias após a aplicação dos herbicidas (DAT), adotando-se escala visual, em que a ausência de injúria correspondeu ao valor 0 , enquanto a morte da planta correspondeu ao valor 100 . Após a última avaliação visual, as plantas foram coletadas individualmente, acondicionadas em saco de papel e levadas ao secador com circulação de ar quente de $60{ }^{\circ} \mathrm{C}$. Após uma semana, foi determinada a massa das plantas desidratadas.

Os resultados foram submetidos à análise de variância e, quando o teste F para tratamentos foi significativo, realizou-se a comparação das médias pelo teste $\mathrm{t}$ (DMS) em nível de 5\% de probabilidade do erro experimental.

No segundo experimento, realizado para confirmar a resistência ao produto sethoxydim, utilizou-se o biótipo suspeito de resistência e o suscetível, já descritos. As condições de cultivo das plantas foram estabelecidas conforme já descrito anteriormente. Os tratamentos foram organizados num esquema fatorial hierárquico e o delineamento foi o DIC com três repetições. Os biótipos resistente e suscetível foram o primeiro fator; e o segundo foram as concentrações de sethoxydim. Para o biótipo suspeito de resistência, as concentrações do herbicida foram de $0,7,14,28,56$, 112 e 182 mM; e para o biótipo suscetível foram: $0 ; 1,75 ; 2,1 ; 3,5 ; 5,25 ; 7 ;$ e $112 \mathrm{mM}$. A concentração de $7 \mathrm{mM}$ corresponde à dose usualmente recomendada no campo, assumindo o volume de calda de $100 \mathrm{~L} \mathrm{ha}^{-1}$. Aos tratamentos foi adicionado óleo mineral na concentração de 1,5\%. A aspersão do herbicida e a avaliação do efeito dos tratamentos seguiram os métodos já descritos anteriormente.

No terceiro experimento, realizado para validar alguns dos resultados do primeiro, utilizou-se apenas o biótipo suspeito de resistência, avaliando sua resposta às concentrações de clethodim e fluazifop. Novamente empregou-se esquema fatorial hierárquico para 
arranjo dos tratamentos num DIC com três repetições. Para o herbicida clethodim as concentrações foram: $0 ; 3,3 ; 6,6 ; 13,2 ; 26,4$; e 39,6 mM; e para o herbicida fluazifop: 0; 3,8 ; 7,$6 ; 15,2 ; 30,4$; e 45,6 mM. As concentrações 3,3 e 3,8 mM correspondem às doses de $120 \mathrm{e}$ $125 \mathrm{~g} \mathrm{ha}^{-1}$ de clethodim e de fluazifop, respectivamente, assumindo a vazão de $100 \mathrm{~L} \mathrm{ha}^{-1}$. Aos tratamentos foi adicionado óleo mineral na concentração de 1,5\%. A aspersão do herbicida e a avaliação do efeito dos tratamentos seguiram os métodos já descritos anteriormente. No momento da aspersão dos herbicidas as plantas apresentavam quatro a cinco folhas $(2 \mathrm{~cm}$ de estatura), a temperatura do ar era de $32{ }^{\circ} \mathrm{C}$ e a umidade relativa do ar de 54\%.

Os resultados desses dois experimentos de resposta à dose foram submetidos à análise de variância e realizou-se ajuste às equações que melhor explicassem os resultados. Para o experimento comparando biótipos, a partir das equações determinou-se a $\mathrm{MS}_{50}$, ou seja, determinou-se a dose necessária para reduzir em $50 \%$ o valor da massa das plantas desidratadas. O fator de resistência (FR) foi calculado pelo quociente entre a $\mathrm{MS}_{50}$ do biótiopo suspeito de resistência ao sethoxydim e a $\mathrm{MS}_{50}$, do biótipo suscetível. Estará confirmada a resistência quando FR > 1,0 (Saari et al., 1994).

Um último experimento foi realizado com a população resistente para investigar a ocorrência de resistência cruzada para outros inibidores de ACCase ainda não avaliados no primeiro experimento anteriormente descrito. Utilizou-se delineamento inteiramente casualizado com três repetições. Aos 20 dias após o transplante das plantas, quando estas apresentavam um afilho, aplicaram-se os herbicidas e respectivas concentrações/doses: butroxydim (2,3 mM = $94 \mathrm{~g} \mathrm{ha}^{-1}$, marca comercial Falcon), clethodim (3,3 mM = $120 \mathrm{~g} \mathrm{ha}^{-1}$, marca comercial Select), fenoxaprop (5,3 mM = $144 \mathrm{~g} \mathrm{ha}^{-1}$, marca comercial Furore); fenoxaprop-p $\left(3,25 \mathrm{mM}=110 \mathrm{~g} \mathrm{ha}^{-1}\right.$, marca comercial Podium); 2,5 mM = $82 \mathrm{~g} \mathrm{ha}^{-1}$, marca comercial Whip-S); e propaquizafop $\left(2,7 \mathrm{mM}=125 \mathrm{~g} \mathrm{ha}^{-1}\right.$, marca comercial Shogum). Em todas as soluções herbicidas foi adicionado o óleo mineral Assist, na concentração de 1,5\%. Todas as concentrações selecionadas neste experimento corresponderam àquelas usualmente indicadas para uso no campo. A aplicação dos herbicidas, a avaliação dos tratamentos e a análise estatística dos resultados seguiram os métodos já descritos.

\section{RESULTADOS E DISCUSSÃO}

São apresentados na Tabela 1 os resultados de controle de ELEIN a partir dos 21 DAT. Nesse período já se observam diferenças entre os tratamentos herbicidas e nota-se, em relação à testemunha, bom controle (>70\%) das plantas de ELEIN com os produtos quizalofop e clethodim, seguido por fluazifop e haloxyfop. Nesse período de avaliação ocorreu controle inferior a 60\% com os herbicidas cyhalofop, fenoxaprop e sethoxydim. Esses resultados persistiram nas avaliações realizadas aos $28 \mathrm{e}$ 35 DAT.

Nas avaliações realizadas aos 35 DAT fica evidente a falta de controle do biótipo de Eleusine indica originário do Mato Grosso, principalmente para os herbicidas fenoxaprop e sethoxydim, e controle médio (55\%) para o herbicida cyhalofop. Os demais herbicidas avaliados controlaram essa espécie (Tabela 1).

A massa da planta desidratada reflete aproximadamente as mesmas observações relatadas aos 35 DAT; as plantas que sobreviveram ao controle químico continuaram seu desenvolvimento, comparadas à testemunha. Assim, foram ineficazes no controle de ELEIN os tratamentos com sethoxydim, fenoxaprop e cyhalofop. Nos demais tratamentos houve mortalidade dos vegetais e as plantas encontravam-se secas durante a última avaliação.

Em virtude do resultado apresentado na Tabela 1, o experimento seguinte foi realizado comparando-se o biótipo suspeito de resistência com o suscetível, utilizando-se diversas concentrações do herbicida sethoxydim (Figura 1). Os resultados de controle avaliados aos 7, 14, 21 e 28 DAT não são apresentados porque não indicaram evidências diferentes das verificadas com massa de plantas desidratadas.

Os resultados obtidos com o biótipo suscetível, oriundo de Porto Alegre-RS, possibilitaram ajustar equação linear para as concentrações até $7 \mathrm{mM}$, equivalente à máxima utilizada no campo. A equação linear explica até $88 \%$ dos resultados obtidos. Essa equação 
indica que a resposta dos vegetais foi linear ao aumento da concentração do herbicida e que para cada mM de incremento na concentração do herbicida houve redução de 0,33 g na massa seca das plantas de ELEIN (Figura 1).

Resultado linear também foi obtido com o biótipo oriundo do Mato Grosso e suspeito de resistência. Contudo, para este biótipo foi possivel fazer ajuste linear para concentrações de até $182 \mathrm{mM}$, com $\mathrm{R}^{2}$ de $87 \%$. Nota-se que, para o biótipo suspeito de resistência, a concentração máxima testada corresponde a 26 vezes aquela recomendada no controle em nível de campo. Para este biótipo, o herbicida, de fato, necessitou de maior concentração para controle efetivo da planta de ELEIN. Para cada $\mathrm{mM}$ de incremento na concentração de sethoxydim, a massa das plantas desidratadas reduziu 0,015 g (Figura 1).

A Figura 1, originada a partir dos dados sobre o efeito do herbicida sethoxydim em dois biótipos de ELEIN, indica que a $\mathrm{MS}_{50}$ (concentração necessária para reduzir 50\% da massa seca das plantas) para o biótipo suspeito de resistência foi de $95 \mathrm{mM}$, enquanto a $\mathrm{MS}_{50}$ para o biótipo suscetível foi de 5,15 mM. Esses resultados confirmam que o biótipo oriundo do Mato Grosso é resistente ao sethoxydim e que o FR, também conhecido como índice de resistência ou taxa de resistência, para este é de 18,4 . Isso significa que o biótipo do Mato Grosso é dezoito vezes menos sensível ao sethoxydim do que o biótipo suscetivel utilizado para comparação (de Porto Alegre-RS).

Os resultados da Figura 1 não evidenciam diferenças de matéria seca das plantas do biótipo suscetível e do resistente não tratadas com herbicida. Esse resultado sugere que não há penalidade (menor aptidão ecológica) associada ao mecanismo de resistência.

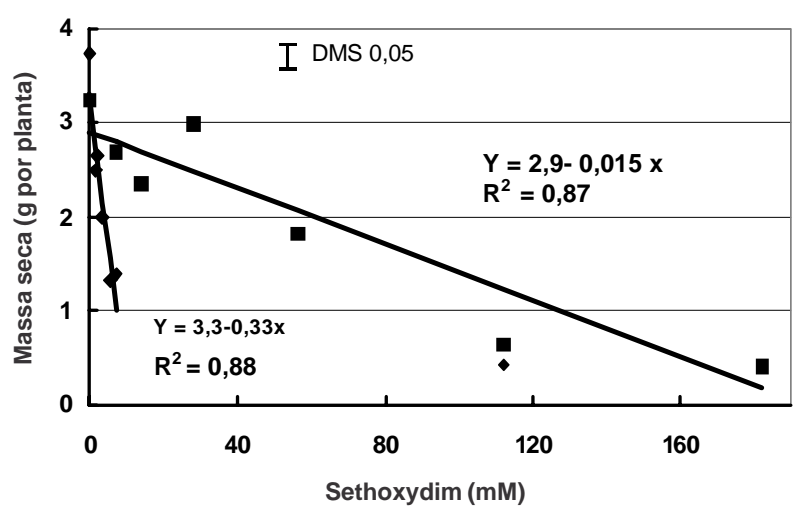

Barra vertical representa a diferença mínima significativa, no nível de probabilidade indicada, para comparar quaisquer tratamentos.

Figura 1 - Massa de planta desidratada (g por planta) para biótipos de Eleusine indica suscetível (i ) e resistente ( ao herbicida sethoxydim.

Tabela 1 - Controle (\%), avaliado aos 21, 28 e 35 dias após a aplicação dos tratamentos (DAT), e massa das plantas desidratadas de Eleusine indica oriundas do Mato Grosso. Média de três repetições

\begin{tabular}{|c|c|c|c|c|c|}
\hline Tratamento & $\begin{array}{l}\text { Concentração } \\
(\mathrm{mM})\end{array}$ & $\begin{array}{c}\text { Controle }(\%) \\
21 \text { DAT }\end{array}$ & $\begin{array}{c}\text { Controle (\%) } \\
28 \text { DAT }\end{array}$ & $\begin{array}{c}\text { Controle }(\%) \\
35 \text { DAT }\end{array}$ & $\begin{array}{c}\text { Massa seca } \\
\text { (mg por planta) }\end{array}$ \\
\hline Clethodim & $3,3^{\frac{1 /}{}}$ & $80 \quad \mathrm{~B}^{2 /}$ & $95 \quad \mathrm{a}$ & $100 \quad \mathrm{a}$ & $120 \mathrm{e}$ \\
\hline Cyhalofop & 15,9 & $35 \mathrm{~d}$ & $60 \quad b$ & 55 & 630 \\
\hline Fenoxaprop-p & 6,5 & 15 & $16 \mathrm{~d}$ & 15 & 1.120 \\
\hline Fluazifop & 7,6 & 70 & 95 & 98 & 150 \\
\hline Haloxyfop & 4,9 & 75 bc & 95 & 100 & 100 \\
\hline Quizalofop & 2,9 & 95 & $95 \quad \mathrm{a}$ & 100 & 30 \\
\hline Sethoxydim & 7,0 & 15 & $25 \mathrm{c}$ & 20 & 1.570 \\
\hline Testemunha & --- & $0 \mathrm{f}$ & $5 \mathrm{e}$ & $10 \mathrm{e}$ & $2.500 \quad \mathrm{a}$ \\
\hline $\mathrm{CV}^{3 /}$ & --- & 6,3 & 1,7 & 1,6 & 27,6 \\
\hline DMS & --- & 5,2 & 1,7 & 1,7 & 374 \\
\hline QME & --- & 9,375 & 1,041 & 1,041 & 46 \\
\hline
\end{tabular}

1/ Concentrações correspondem respectivamente às seguintes doses, assumindo volume de calda de $100 \mathrm{~L} \mathrm{ha}^{-1}: 120 \mathrm{~g} \mathrm{ha}^{-1} ; 240 \mathrm{~g} \mathrm{ha}^{-1} ; 220 \mathrm{~g} \mathrm{ha}^{-1}$; $250 \mathrm{~g} \mathrm{ha}^{-1} ; 180 \mathrm{~g} \mathrm{ha}^{-1} ; 100 \mathrm{~g} \mathrm{ha}^{-1}$; e $220 \mathrm{~g} \mathrm{ha}^{-1}$.

2/ Médias na coluna seguidas pela mesma letra não diferem entre si pelo teste $\mathrm{t}$ (DMS) a $5 \%$ de probabilidade do erro experimental.

³/ $\mathrm{CV}=$ coeficiente de variação; DMS = diferença mínima significativa; QME = quadrado médio do erro experimental. 
O experimento seguinte envolveu a comparação entre os herbicidas fluazifop e clethodim na sua eficácia no controle do biótipo resistente ao sethoxydim e serviu para validar os resultados do primeiro experimento (Figura 2). Para ambos os herbicidas não houve interação com as doses testadas, indicando comportamento similar entre os produtos e as doses utilizadas. Ou seja, à medida que ocorreu elevação da concentração do herbicida, foi verificada redução da matéria seca, a qual foi drástica já para as primeiras doses testadas; concentrações similares àquelas utilizadas no campo foram suficientes para controle dos indivíduos. Para esses resultados não foi possível fazer o ajuste linear ou sigmoidal entre concentração e matéria seca produzida, provavelmente devido à escolha das doses utilizadas.

No experimento apresentado na Tabela 2 avaliou-se o controle aos 10 e 20 DAT proporcionado por diversos herbicidas inibidores de ACCase. Neste trabalho, os resultados indicam que a avaliação feita aos 10 DAT foi inadequada para diferenciar os herbicidas. Na avaliação realizada aos 20 DAT, constatou-se que nenhum dos herbicidas controlou adequadamente ELEIN resistente ao sethoxydim. Contudo, é provável que com o decorrer do tempo apenas clethodim propiciasse controle do biótipo ELEIN (Tabela 2).

Muitos autores já publicaram resultados com biótipos de Eleusine indica resistentes aos

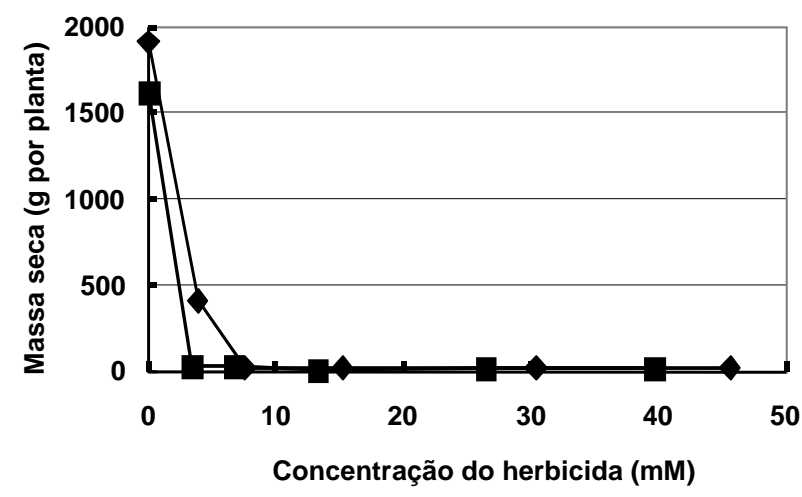

Barra vertical representa a diferença mínima significativa, no nível de probabilidade indicada, para comparar quaisquer tratamentos.

Figura 2 - Massa de planta desidratada (g por planta) para o biótipo oriundo do MT, aspergido com diferentes concentrações de clethodim (i ) e fluazifop ( $\mathbf{\square})$.
Tabela 2 - Controle (\%), avaliado aos 21, 28 e 35 dias após a aplicação dos tratamentos (DAT), e massa seca das plantas de Eleusine indica oriundas do Mato Grosso. Média de três repetições

\begin{tabular}{|c|c|c|c|c|}
\hline Tratamento & $\begin{array}{c}\text { Concentraçãa } o^{1 /-} \\
(\mathrm{mM})\end{array}$ & $\begin{array}{c}\text { Controle } \\
(\%) \\
10 \mathrm{DAT}\end{array}$ & $\begin{array}{l}\text { Controle } \\
(\%) \\
20 \mathrm{DAT}\end{array}$ & $\begin{array}{c}\text { Massa seca } \\
\text { (mg por planta) }\end{array}$ \\
\hline Butroxydim & 2,3 & 10,00 & 11,67 & 0,2303 \\
\hline Clethodim & 3,3 & 21,66 & 40,00 & 0,5213 \\
\hline Fenoxaprop & 5,3 & 10,00 & 5,00 & 0,3947 \\
\hline Fenoxaprop-p & 3,25 & 5,00 & 5,00 & 0,3707 \\
\hline Fenoxaprop-p & 2,5 & 5,00 & 5,00 & 0,3030 \\
\hline Propaquizafop & 2,7 & 26,66 & 20,00 & 0,3210 \\
\hline $\mathrm{CV}^{2} \underline{\prime}$ & $\ldots$ & ns & ns & $\mathrm{ns}$ \\
\hline DMS & - & ns & ns & ns \\
\hline QME & --- & $\mathrm{ns}$ & ns & $\mathrm{ns}$ \\
\hline
\end{tabular}

${ }^{1}$ Concentrações correspondem, respectivamente, às seguintes doses, assumindo volume de calda de $100 \mathrm{~L} \mathrm{ha}^{-1}$ : $94 \mathrm{~g} \mathrm{ha}^{-1} ; 120 \mathrm{~g} \mathrm{ha}^{-1} ; 144 \mathrm{~g} \mathrm{ha}^{-1}$ (Furore); $110 \mathrm{~g} \mathrm{ha}^{-1}$ (Podium); $82 \mathrm{~g} \mathrm{ha}^{-1}$ (Whip-S); e $125 \mathrm{~g} \mathrm{ha}^{-1}$.

${ }^{2} \mathrm{CV}=$ coeficiente de variação; DMS = diferença mínima significativa; $\mathrm{QME}=$ quadrado médio do erro experimental.

herbicidas. Os primeiros casos de resistência para esta espécie vegetal foram documentados para os herbicidas inibidores de mitose (inibidores da polimerização de tubulina), e o mecanismo de resistência se deve ao local de ação do herbicida alterado (Mudge et al., 1984; Leach et al., 1995).

Local de ação alterado também é a causa da resistência de Eleusine indica aos inibidores de ACCase encontrada na Malásia. Como no presente trabalho, também não houve resistência cruzada para todos os herbicidas inibidores de ACCase (Heap, 2005). Também existem registros de Eleusine indica resistente a ghlyphosate, o que leva à suspeita de que o mecanismo de resistência também seja insensibilidade no local de ação do herbicida (Heap, 2005).

Resistência cruzada se refere àquele biótipo que não é controlado por nenhum herbicida que atua em determinada enzima. Como a resistência aos inibidores de ACCase normalmente não é cruzada, especula-se que o local de ligação do herbicida na enzima não seja exatamente o mesmo para todos os herbicidas e que a resistência somente se manifesta para aqueles produtos que dependem de determinado local na enzima, onde houve a mutação (em relação ao biótipo selvagem), para sua ligação (Cortez, 2000). 
No mundo, as principais mutações registradas na ACCase e que conferem resistência aos herbicidas ocorrem em cinco pontos na enzima. Infelizmente não há detalhes sobre a resistência cruzada para comparar com os resultados obtidos neste trabalho, de forma que possibilitasse hipotetizar sobre o local de ocorrência de mutação no biótipo oriundo do MT. Neste trabalho, a confirmação de ocorrência de resistência cruzada para os herbicidas sethoxydim, butroxydim, cyhalofop, propaquizafop e fenoxaprop (Figura 1 e Tabelas 1 e 2) e ausência de resistência para os demais herbicidas inibidores de ACCase disponiveis no Brasil (clethodim, fluazifop e haloxyfop Tabela 1) é utilizada como evidência indireta para resistência devido à mutação na enzima ACCase; entretanto, mais evidências devem ser obtidas para confirmar essa hipótese.

Deve-se salientar que outros mecanismos de resistência também já foram detectados em ELEIN. Por exemplo, a resistência de alguns biótipos desta espécie aos inibidores de ALS ainda possui mecanismo desconhecido (Heap, 2005). Da mesma forma, há registros de biótipos de Eleusine indica resistentes aos inibidores do fotossistema I, em que o mecanismo de resistência ainda não foi determinado (Heap, 2005).

Finalmente, a metabolização como mecanismo de resistência aos inibidores de ACCase foi detectada na Austrália em biótipos da espécie Lolium rigidum com habilidade de metabolizar diclofop (Menendez et al., 1996). Da mesma forma, na Inglaterra, biótipos de Alopecurus myosuroides insensiveis ao diclofop e ao fenoxaprop eram capazes de detoxificar estes produtos (Hall et al., 1994).

Outros autores, no Brasil, também já evidenciaram resistência cruzada para apenas alguns herbicidas inibidores de ACCase em Brachiara plantaginea (Cortez, 2000). Nesse caso, a autora observou que havia vários biótipos de $B$. plantaginea, cada qual com especificidade em termos de resistência cruzada para alguns herbicidas dentro dos inibidores de ACCase. A autora confirmou que o mecanismo de resistência era devido à mutação no local de ação dos herbicidas através do isolamento da enzima ACCase em plantas de biótipo resistente e suscetível e da verificação da insensibilidade desta aos produtos (Cortez, 2000).

É importante mencionar que, quando do planejamento do experimento de dose-resposta apresentado na Figura 1, pensava-se em ajustar a equação do tipo sigmoidal, como proposto por Souza et al. (2000). No entanto, causou surpresa aos autores o fato de que os resultados não se ajustaram ao modelo sigmoidal e tiveram ajuste linear. Possiveis explicações para isso incluem: a escolha das doses, o número de repetições e o fato de que, nas maiores doses testadas, o herbicida sethoxydim inibe outras enzimas (Lin \& Yang, 1999), talvez modificando o esperado efeito sigmoidal.

Os resultados obtidos neste trabalho indicam a eficácia, no biótipo oriundo do Mato Grosso, de vários herbicidas inibidores de ACCase (Tabelas 1 e 2). Esses dados são promissores, pois indicam que esses produtos que ainda apresentam controle eficiente podem ser utilizados como parte da estratégia para o manejo de Eleusine indica nas áreas onde há presença do biótipo resistente. Contudo, convém alertar que não é recomendável o uso intensivo apenas destes produtos, a fim de evitar que estes atuem como agente de seleção e, dessa forma, sejam obtidos - nestas populações resistentes a alguns herbicidas inibidores de ACCase - biótipos com resistência aos demais produtos do grupo.

Para ELEIN resistente aos inibidores de ACCase também vale o alerta feito por Lamego et al. (2002). Eles evidenciam a dificuldade de controle de B. plantaginea em culturas dicotiledôneas no sistema de semeadura direta. Um dos principais problemas enfatizados pelos autores foi a elevação dos custos, principalmente no caso de resistência cruzada para todos os herbicidas inibidores de ACCase. Além disso, o manejo das plantas daninhas resistentes ficaria dependente de herbicidas de aplicação ao solo, com atividade reduzida naquele sistema de preparo, e, como conseqüência, haveria perda no rendimento de grãos devido à matocompetição (Lamego et al., 2002).

Os resultados obtidos neste trabalho permitem concluir que o biótipo de Eleusine indica oriundo do Mato Grosso apresentou nível variável de resistência em função dos herbicidas inibidores de ACCase testados. O biótipo 
selvagem (de Porto Alegre-RS) foi eficazmente controlado com sethoxydim. No biótipo oriundo do Mato Grosso constatou-se resistência aos herbicidas sethoxydim, butroxydim, fenoxaprop, propaquizafop e cyhalofop. Este biótipo foi eficazmente controlado com clethodim, fluazifop, haloxyfop e quizalofop.

\section{AGRADECIMENTOS}

Ao CNPQ, CAPES e FAPERGS, pelo apoio financeiro ao projeto e aos pesquisadores.

\section{LITERATURA CITADA}

SOUZA, A. S. et al. Uso da equação logística no estudo de dose-resposta de glyphosate e imazapyr por meio de bioensaios. Planta Daninha, v. 18, n. 1, p. 17-28, 2000.

CHRISTOFFOLETI, P. J. et al. Imidazolinone resistant Bidens pilosa biotypes in the Brazilian soybean areas. In: MEETING OF THE WSSA, 1996, Norfolk. Abstracts ... Champaign: WSSA, 1996. p. 10.

CORTEZ, M. G. Resistência de biótipos de Brachiaria plantaginea (Linck) Hitch. a herbicidas inibidores da aceti-coenzima-A-carboxilase. 2000. $213 \mathrm{f}$. Tese (Doutorado em Agronomia) - Universidade de São Paulo, São Paulo, 2000.

CORTEZ, M. G.; MADUREIRA, A.; OVEJERO, R. L. Resistência de Digitaria spp. a herbicidas inibidores da ACCase. In: CONGRESSO BRASILEIRO DA CIÊNCIA DAS PLANTAS DANINHAS, 23., 2002, Gramado. Anais ... Londrina: SBCPD, 2002. p. 191.

GAZZIERO, D. L. P. et al. Resistência de amendoim-bravo aos herbicidas inibidores da enzima ALS. Planta Daninha, v. 16, n. 2, p. 117-126, 1998.

GAZZIERO, D. L. P. et al. Resistência da planta daninha capim-marmelada (Brachiaria plantaginea) aos herbicidas inibidores da enzima ACCase na cultura da soja. Planta Daninha, v. 18, n. 1, p. 169-180, 2000.

HALL, L. M.; TARDIFF, F.; POWLES, S. B. Mechanism of cross and multiple resistance in Alopecurus mysuroides and Lolium rigidum. Phytoprotecion, v. 73, n. 1, p. 17-23, 1994.

HARPER, J. L. The evolution of weeds in relation to resistance to herbicides. In: BRITISH WEED CONTROL CONFERENCE, 3., 1956, Brighton. Proceedings ... Brighton: BCPC, 1956. p. 179-188.

HEAP, I. International survey of resistant weeds. Disponível em: <http://www. weedsciencie.org/in.asp >. Acesso em: 15 maio 2005 .
HILTON, H. W. Herbicide tolerant strains of weeds. HSCPA Annual Report, 1957. p. 66.

KISSMANN, K. G.; GROTH, D. Plantas infestantes e nocivas. São Paulo: Basf Brasileira, 1992. p. 91-195.

LAMEGO, F. P. et al. Resistência de Brachiaria plantaginea aos herbicidas inibidores de ACCase. R. Bras. Herb., v. 3, n. 2/3, p. 162-168, 2002.

LEBARON, H. M.; GRESSEL, J. Herbicide resistance in plants. New York: Wiley-Interscience Publications, 1982. $401 \mathrm{p}$.

LEACH, G. E. et al. Target enzyme- based resistance to acetyl-coenzyme A carboxylase inhibitors in Eleusine indica. Pest. Biochem. Physiol., v. 51, n. 1, p. 129-136, 1995.

LIN, S. W.; YANG, D. Y. Inhibition of 4hydroxyphenylpyruvate dioxygenase by sethoxydim, a potent inhibitor of acetyl-coenzyme A carboxylase. Bioorg. Med. Chem. Letters, v. 9, n. 4, p. 551-554, 1999.

MENENDEZ, J. et al. Diclofop metabolism in resistant biotypes of Lolium rigidum Gaudin. In: PROCCEDINGS OF THE INTERNATIONAL SYMPOSIUM ON WEED AND CROP RESISTANT TO HERBICIDE, 1996, Cordoba. Proceedings... Cordoba: 1996. p. 97-98.

MEROTTO Jr., A. et al. Resistência de Echinochloa sp. ao quinclorac. In: CONGRESSO BRASILEIRO DA CIÊNCIA DAS PLANTAS DANINHAS, 22., 2000, Foz do Iguaçu. Anais... Londrina: SBCPD, 2000. p. 513.

MORRISSETTE, N. S et al. Dinitroanilines bind alphatubulin to disrupt microtubules. Molec. Biol. Cell., v. 15, n. 4, p. 1960-1968, 2004.

MUDGE, L. C.; GOSSETT, B. J.; MURPHY, T. R. Resistance of goosegrass (Eleusine indica) to dinitroaniline herbicides. Weed Sci., v. 32, n. 3, p. 591-594,1984.

NOLDIN, J. A.; EBEHARDT, D. S.; KNOBLAUCH, R. Resistência aos herbicidas em Sagittaria montevidensis: primeiras evidências. In: CONGRESSO BRASILEIRO DE ARROZ IRRIGADO, 1., 1999, Pelotas. Anais... Pelotas: Embrapa, 1999. p. 566-567.

NOLDIN, J. A.; EBERHARDT, D. S.; RAMPELOTTI, F. T. Cyperus difformis L. resistente a herbicidas inibidores da ALS em Santa Catarina. In: CONGRESSO BRASILEIRO DA CIÊNCIA DAS PLANTAS DANINHAS, 23., 2002, Gramado. Anais ... Londrina: SBCPD, 2002a. p. 198.

NOLDIN, J. A.; EBERHARDT, D. S.; RAMPELOTTI, F. T. Fimbristylis miliacea (L.) Vahl resistente a herbicidas inibidores da ALS em Santa Catarina. In: CONGRESSO BRASILEIRO DA CIÊNCIA DAS PLANTAS DANINHAS, 23., 2002, Gramado. Anais ... Londrina: SBCPD, 2002 b. p. 199. 
ROMAN, E. S. et al. Resistência de azevém (Lolium multiflorum) ao herbicida glyphosate. Planta Daninha, v. 22, n. 2, p. 301-306, 2004.

SAARI, L. L.; COTTERMAN, J. C.; THILL, D. C. Resistance to acetolactate synthase inhibiting herbicides. In: POWLES, S. B.; HOLTUM, J. A. M. Herbicide resistance in plants: biology and biochemistry. Boca Raton: CRC Press, 1994. $353 \mathrm{p}$.

SWITZER, C. M. The existence of 2,4-D resistant strains of wild carrot (Daucus carota). In: MEETING OF THE NEWSS, 11., 1957, Newss. Proceedings ... Newss, 1957. p. $315-318$.

TREZZI, M. M. et al. Multiple resistance of acetolactase syntase and protoporphyrinogen oxidade inhibitors in biotypes. J. Environ. Sci. Health, v. B40, n. 1, p. 101-109, 2005.
VIDAL, R. A. Ação dos herbicidas: absorção, translocação e metabolização. Porto Alegre: Evangraf, 2002. 89 p.

VIDAL, R. A.; MEROTTO Jr., A. Resistência de amendoimbravo (Euphorbia heterophylla L.) aos herbicidas inibidores da enzima acetolactato sintase. Planta Daninha, v. 17, n. 3, p. $367-374,1999$.

VIDAL, R. A.; MEROTTO Jr., A. Herbicidologia. Porto Alegre: Evangraf, 2001. 152 p

VIDAL, R. A.; WINKLER, L. M. Euphorbia heterophylla L. resistente aos herbicidas inibidores de ALS: II - distribuição geográfica e caracterização genética de biótipos do planalto do Rio Grande do Sul. R. Bras. Agroc., v. 10, n. 4 , p. 461-465, 2004.

WINKLER, L. M.; VIDAL, R. A.; BARBOSA NETO, J. F. Aspectos genéticos envolvidos na resistência de plantas daninhas aos herbicidas. R. Plantio Direto, v. 70, n. 4 , p. 21-24, 2002. 